\title{
7 \\ Belonging Together: A Model for Education in a New European Age
}

We conclude this book by examining the values of the European Schools System and how these are and can be translated into pedagogic practices. We have already suggested that the system has a framework of values: the eight competences. The rationale, therefore, for the curriculum is and should be that it conforms to these eight competences, leading to the European Baccalaureate: communication in the mother tongue; communication in foreign languages; mathematical competence and basic competences in science and technology; digital competence; learning to learn; social and civic competences; a sense of initiative and entrepreneurship; and cultural awareness and expression. What these competences fundamentally embrace is a set of European, anti-nationalistic and cosmopolitan values, and the sense of supporting the views of marginalized students, teachers and parents in order to develop an appropriate pedagogy to allow an inclusive sense of citizenship (Banks 1997, 1998, 2004). What has happened all too frequently in the history of the European Schools System is the development of a set of inclusive values that can genuinely address the problems of modern education systems, and at the same time, a set of pedagogical values and strategies that are not fit for this important purpose. 
In the first place we need to address those theories that, as educationalists, allow us to provide education in a diversity of contexts, recognise the citizenship of minority groups and promote democracy. This means that policy-makers within the system need to address issues such as citizenship, human rights, utopian perspectives, cosmopolitanism and democracy in a pedagogic context. Cosmopolitanism has a long lineage, having roots in ancient Greek philosophy and the European Enlightenment. The cosmopolitan perspective is an ideal that 'combines a commitment to humanist principles and norms, an assumption of human equality, with a recognition of difference, and indeed a celebration of diversity' (Kaldor 2003: 19).

Though emblematic of the ancient Greek Enlightenment, the political culture portrayed in the writings of Plato and Aristotle is not cosmopolitan. Here, a man (and the citizen here is thought of as exclusively male) identifies himself first and foremost as a citizen of a particular polis, and his allegiance is to a set of institutions and a body of people, rather than to any supra-national or worldly entity. This allegiance required him to defend the polis from attacks, abide by decisions made by its democratic institutions, and contribute to the common good of its people. In addition, the virtuous citizen was not expected to share with or serve those living outside the city walls. The good Athenian was privileged over the foreigner, and in a similar way, the freeman had rights and responsibilities that were superior to those held and discharged by women, children and slaves. This is a limited form of cosmopolitanism.

However, Platonism and Aristotelianism do not represent the totality of ancient Greek thought; and there were certainly many Greek thinkers who embraced some of the tenets of cosmopolitanism. Xenophobic beliefs and practices, though endorsed by many in the ancient Greek polis, were not uniformly accepted or advocated. Yet even as Plato and Aristotle were writing, other Greeks were enthusiastically arguing for forms of cosmopolitanism and refusing to accept that the foreigner should be demonized. Traveling intellectuals, such as Herodotus and Thales, argued for a way of life that was both enlightened in an intellectual sense and respected the rights and freedoms of humanity. Socrates, too, was sensitive to this sense of universalism, or at least this is how Plato understood his thinking. Socrates was concerned with a notion of self- 
and other-examination, with these examinations being understood in both a personal and political sense, extending to Athenians and foreigners alike.

Stoic cosmopolitanism in its various guises was enormously persuasive throughout the Greco-Roman world. Although the term cosmopolitan

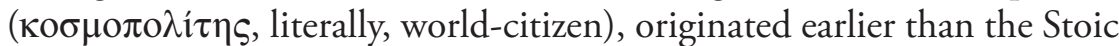
philosophers, it was these philosophers who gave meaning to the term, even if that meaning is somewhat different from the way it is used now. As early as 340 BC Diogenes the Cynic (1925a) described himself as 'a citizen of the world' (in Greek, kosmopolites), and Antiphon (1965), a little later, wrote that 'by nature we are all constituted alike in all things, both barbarians and greeks. ... This can be seen by consideration of those things which are essential by nature to all men. In these things no barbarian is set apart from us, nor any Greek. For we all breathe into the air through mouth and nostrils ...' Zeno (1925b), in his Republic, was reported by Plutarch as saying: '(m)oreover, the much-admired Republic of Zeno, the founder of the Stoic sect, may be summed up in this one main principle: that all the inhabitants of this world of ours should not live differentiated by their respective rules of justice into separate cities and communities, but that we should consider all men to be of one community and one polity, and that we should have a common life and an order common to us all, even as a herd that feeds together and shares the pasturage of a common field'. Stoic philosophers later offered a dual notion of citizenship, that of the local polis, city-state or nation complemented by that of the kosmos (universe or world). This is redolent of the modern notion of layered citizenship, embracing local and global elements, including a notion of Europeanism. This sense of common humanity, reflected in our ability to reason, was later seen as a principle of natural law, and the philosopher, John Locke (2007 [1689]), at a much later point in time, used it to develop a notion of a universal code of justice and an idea that human beings have inalienable rights regardless of what governments said and did.

Stoic cosmopolitanism made many people more receptive to the cosmopolitan ideal and thus contributed greatly to its widespread influence. Cosmopolitanism slowly emerged as a key theme of the European Enlightenment, exemplified in the writings of the renowned international 
scholar, Erasmus of Rotterdam. Erasmus explicitly drew on ancient cosmopolitan texts to argue for the ideal of a world-wide peace. The emphasis here was on the indivisibility of human beings in contrast to dividing peoples into states, religions, races, castes or any other grouping, and then describing these divisions as natural kinds. Erasmus pleaded in effect for national and religious tolerance (cf. Querela Pacis, Erasmus Desiderius 2017).

There were many reasons for the emergence of cosmopolitan ideas during the European enlightenment: the increasing growth of capitalism and world-wide trade; empire building and the early manifestations of globalisation; the exploration and settlement of hitherto inaccessible parts of the world; the renewed interest in Hellenistic philosophy (though this was limited to Ancient Greek speakers); and the emergence of a notion of human rights with a focus on human reason. Many intellectuals at this time gave their allegiance to membership of an informal network of transnational thinkers, rather than to a nation state, or city or polis. This prepared them to think in terms other than those of states and peoples and adopt a cosmopolitan perspective. Under the influence of the American Revolution, and especially during the first years of the French Revolution, cosmopolitanism as an idea underwent a revival. The 1789 declaration of human rights grew out of cosmopolitan modes of thinking and reinforced them in turn.

These early forms of globalised thinking and globalised practices took a number of forms. Globalising processes, in so far as they have real effects (we also have to take account of vernacular pressures), work in two ways: firstly, national governments operate within global markets and therefore fashion their policies to fit this agenda or to exploit it; and secondly, national governments are subject to pressure from forces outside their jurisdiction that influence their policies and practices. Further to this, the success of any intervention or experiment (by the state or another body operating outside the state), or at least the path it takes, is not just determined by the system into which it is being introduced but also by the type of intervention that is being made. Interventions and experiments are time sequenced, so that they are likely to have different effects at different moments in the history of a country or continent such as Europe. 
Globalisation works in a number of distinctive ways, and this means that social objects and social mechanisms operate in open systems and therefore have particular properties, including generative causal powers. McLaren and Farahmandpur (2001), for example, have suggested that globalisation is a cultural phenomenon and can only be recognised by changes to the forms these cultural phenomena take. So that instead of distinct national forms and identities, there is a cross-fertilisation of ideas, a creation of hybrid cultural forms, an homogenisation of culture, and a standardisation of cultural products. This leads to a sense of cultural sameness or conformism. Globalisation also points to the establishment of globalised markets and global consumer identities.

A second manifestation is that of the expanding nature of capitalization. This can take a number of forms. For example, it may be spatial as capital seeks to fill all the possible social, geographical and physical spaces available to it. Capitalization may also expand through the invention of new types of commodity. And the third form it might take is where capital expands through what might be called intensification; it deepens and develops its influence in the world.

In the eighteenth century, the terms, 'cosmopolitanism' and 'world citizenship', were not thought of as belonging to coherent frameworks of ideas, but rather they pointed to an attitude of open-mindedness and impartiality. A cosmopolitan was someone who did not subscribe to a particular religious or political authority. The term was sometimes used to refer to a person who had a network of international contacts, or felt at home in the world, rather than in the nation or locality in which they were born. In this sense the Encyclopédie suggested that a cosmopolitan was a 'man of no fixed abode, or a man who is nowhere a stranger'. The Encyclopédie, or dictionnaire raisonné des sciences, des arts et des métiers (Encyclopaedia, or a Systematic Dictionary of the Sciences, Arts, and Crafts) was an attempt by leading Enlightenment figures to represent a new way of thinking, as is evidenced by Denis Diderot (1751-1772) argument that the Encyclopédie's aim was to 'change the way people think'. As the editor, he wanted to collect together all the world's knowledge and present it in a value-free and impartial form.

The authors of the various entries to the Encyclopédie drew on the Stoic tradition to formulate an Enlightenment version of cosmopolitanism, 
which gave precedence to a positive moral ideal in the form of a universal human community. This community is characterized by the principles of freedom, equality and lawful behaviour. These common laws, however, are moral laws grounded in reason. Immanuel Kant (1992) also developed the concept of cosmopolitan law, suggesting a third sphere of public law, in addition to constitutional law and international law, in which both states and individuals have rights, and where individuals have these rights as citizens of the earth rather than as citizens of particular states. Global migratory movements have brought about a situation where national citizenship is often exclusionary. However, as John Dewey noted, the identification of citizenship with the powerful discourse of nationality occurred at a specific point in history, the late nineteenth century, when imperialism flourished and democracy was reserved for a minority. In addition, Dewey recognized that cosmopolitanism is a learned perspective. Education can develop the capacity of people to identify with fellow human beings irrespective of national boundaries and develop what Appiah (2007: 82) calls 'a concern for strangers'. The European Schools System has embraced this sense of cosmopolitan identity, though its founders understood it as a European ideal and perhaps more importantly, as a pedagogic process.

\section{Learning Environments}

Acquiring a cosmopolitan identity (and certainly a European one) is a learned activity and requires the development of appropriate learning mechanisms in specialised environments, such as in the European School System, and this calls for an engagement with learning and learning environments. Theoretical and contextual considerations impact, then, on how elements of teaching and learning are realised. Acknowledging this allows the identification of a number of learning models: assessment for learning, observation, coaching, goal-clarification, mentoring, peer learning, simulation, instruction, concept-formation, reflection, metacognitive learning, problem solving, and practice. And each of these in turn is underpinned by a particular theory of learning. What this means is that any model of learning that is employed is constructed in relation 
to particular views of how we can know the world and what it is. These models or learning sets (and this includes feedback mechanisms of a particular kind) give different emphases to the various elements of a learning process.

The first of these models is the assessment for learning model. Assessment for learning can be presented as five key strategies and one cohering idea. The five key strategies are: engineering effective classroom discussions, questions, and learning tasks; clarifying and sharing learning intentions and criteria for success; providing feedback that moves learners forward; activating students as the owners of their own learning; and activating students as instructional resources for one another (Wiliam and Thompson 2008). And the cohering idea is that evidence about student learning is used to adapt instruction to better meet learning needs; in other words, teaching is adaptive to the student's learning needs and evidence from the assessments is used by teachers, learners, or their peers to improve instruction (ibid.).

An important aspect of this model is the active engagement of the learner in the learning process as both an initiator and user of feedback. The key then is the relationship between assessment (designed as formative and developmental) and learning. In this sense feedback is on-going and an integral part of assessment. The assessment for learning movement has been criticised on three grounds: the focus on formative assessment has inevitably marginalised other learning elements; as a result, some of the strategies are both misunderstood and consequently misapplied, for example, peer learning does not amount to asking students to make quantitative judgements about their colleagues' work in relation to a set of criteria; and the reductive process for the purposes of quantifying and comparing results may have led to a distorted understanding of the process of learning.

The second learning set is an observation model. Here the teacher displays the action which the learner is required to imitate in the classroom, and then later in the context of application. There are three principal types: a live model involving a demonstration or acting out of the behaviours to be learnt; a verbal instructional model where this comprises descriptions and explanations of behaviours; and a symbolic model, examples of which are scenarios and expressive performances. These are 
stimuli for learning. The learning skills required of the learner are: observing a performance by the teacher, whether this comprises live modelling, verbal instruction or symbolic modelling; comparing the performance with an embodied form of that display already held by the learner; adjusting their current construct through modification or substitution; practice by the learner whilst being supported within the artificial environment; practice by the learner without support within the artificial environment; transferring the skill to the real environment whilst being supported; and consolidation without support through use in the real environment (cf. Bandura 1977). This model is underpinned by a cognitivist theory of learning.

The third of these is a coaching model. Here the focus is on a series of steps: modelling by the expert; coaching whilst the learner practices; scaffolding where the learner is supported during the initial stages with that support gradually being withdrawn as the learner becomes more proficient (coaching here involves the teacher in identifying for the learner deviations from the model in the performance of the learner, and then supporting the learner as they make attempts to correct this performance); articulation by the learner of that process; reflection on those processes and comparison with the expert's reasons for action; and exploration where the learner undertakes the various activities without support (cf. Collins et al. 1989). Coaching can be seen as a one-to-one activity, or as a collective exercise within a community of practice. This model better fits a socio-cultural theory of learning.

A fourth model involves clarifying and sharing learning intentions and criteria for success with the student over a period of time. To this end, teachers provide learners with explicit statements and explanations about the instructional objectives in a lesson or series of lessons (Zimmerman and Schunk 2011). Goal clarity has three learner-focused dimensions: explanations about how they are expected to perform the tasks assigned to them; opportunities for them to grasp what is expected of them; and reflections about their capacity as self-directed learners in the completion of the task. This mechanism comprises a number of processes: identifying the standard and interpreting its meaning; providing a description with the learner of their mastery of that standard, which should allow the identification of weaknesses in their capacity and the 
means for ameliorating these weaknesses; record-keeping for further identification of the learner's current capability; reflection on this and the identification of the means of improving; and a meta-reflective record of progress in the curriculum (Meece et al. 2006).

A fifth model is mentoring. This supports the informal transmission of content knowledge, social capital or psychosocial resources. It is usually conducted face-to-face and involves a relationship between two people, one of whom is considered to have greater knowledge, wisdom or experience. Five possible mentoring techniques have been identified (cf. Aubrey and Cohen 1995): supporting the learner and taking part in the same activity and learning side-by-side with them; preparing the learner for the future even if they are not ready or able to learn what is being offered to them in the present; catalysing learning so that it provokes a different way of thinking, a change in identity or a re-ordering of values; showing through personal example; and finally, helping and supporting the learner in reflecting back on their previous learning. The terms, coaching and mentoring, are often used synonymously, however, important distinctions between these two approaches can be identified. In distinguishing between these two terms, Clutterbuck and Megginson (2005) identify three specific differences in terms of emphasis: time-scale, approach and context. For example, coaching is focused on performance change whilst mentoring is focused on managing elements of the life-course; and coaching is focused on the immediate context whereas mentoring involves enlarging a learner's networks. In addition, coaching is typically seen as of much shorter duration and in response to a specific goal, whereas mentoring considers immediate issues as part of long-term change. Both mentoring and coaching are about achieving change, and place a strong emphasis on the development of learner self-regulation through the use of appropriate tools, such as critical reflection and scaffolded support.

A sixth model of learning is peer learning. The other forms of learning comprise unequal relations between the teacher and the learner. Here the assumption is made that the learning relationship is between equals, and thus a different form of learning is implied. Examples of this type of learning include: being offered emotional support if learning proves to be difficult and this is always a better form of support if given by someone who is going through the same learning process; dyadic performance 
confrontations, where learning is provoked by confrontational exchanges between learners so that each individual can test their theories, ideas and constructs against those held by other learners engaging in the same type of learning; pair-problem-solving, where learning is enabled through cooperation between two learners of roughly equal standing, so that in a problem-solving exercise, better solutions are forthcoming because there are two problem-solvers rather than one; reciprocal peer tutoring, where non-expert tutoring between equals has the advantage of each person being able to make their own evaluation of the advice being offered unencumbered by status or hierarchy; and scripted cooperative dyads, where peer engagement is focused on the joint production of a script, artefact, performance or text with the advantage that alternative and new interpretations/readings are forthcoming (cf. Falchikov 2001).

A seventh model of learning involves simulation. Simulation is a reproduction of an event or activity, conducted outside the environment in which that event or activity usually takes place. Simulations can be produced through computer games, role-plays, scenarios, presentations and affective and conceptual modelling. The purpose of this learning process is to simulate a real event, and this is to allow the person or persons taking part in that simulation to explore it, to experiment within it, to understand the process, to begin the process of internalisation, to experience albeit in a limited way the emotions and feelings that would normally accompany the experience in real-life, and fundamentally, to allow learning to take place through trial and error and making mistakes in safe situations, which do not have the consequences they would have in real-life situations. Simulations compress time and remove extraneous detail. They are immersive learning experiences, where skills and performances can be enhanced in a way that is not possible outside the simulation. Simulation is an element of learning that has implications for all the theories of learning that have been identified above. As a consequence of the simulative effect the pedagogic object is different in some fundamental respects from the original learning object.

In the instructional model the teacher needs to: gain the attention of the group of learners; inform the learners of the objectives of the learning exercise; stimulate recall of prior learning amongst the group of learners, so that the new information is related productively to previous and 
current learning; present content to the learner; implement appropriate scaffolding processes; stimulate a performance by the learner; provide feedback to the learner which is a comment on their performance and allows corrective action to take place; and evaluate the corrected performance (cf. Gagné 1985). Cognitivist theorists of learning commonly advocate instructional models of learning, because of the emphasis they place on invariant knowledge objects and schematic adjustments to accommodate these objects.

A concept-formation learning process focuses on the re-forming of the conceptual schema held by the learner and one version of it is underpinned by an inferentialist pragmatist philosophy (cf. Brandom 2000). This positions knowledge and knowledge-development within networks of meaning, which are social in character and historical in origin. Learning is complex and potentially rich and rewarding, where the learner is presented with a mass of information, ideas, and opinions from a number of different sources (i.e. books, articles, lectures, seminars, emails, eseminars, personal communications and so on). What the learner does is shape this mass of information, and this shaping can take a number of different forms: partial shaping, complete shaping, discarding with no replacement, confusion, on-going, going backwards and forwards and so on. Shaping takes place against a scholarly background; aspects of which may or may not be implicit and where some but not all of its aspects can be surfaced for deliberation. Conceptual learning is irredeemably social, embedded, and selective. So the learner has to absorb some of the ideas they are presented with and discard or partially discard others. Again, this notion of concept-formation has elements of socio-cultural theories of learning.

Reflection is a seminal form of learning. It has been variously described as critical reflection, reflective practice, reflective thinking and reflexivity. Whereas some see these terms as interchangeable and as having similar meanings, others have sought to differentiate between different types and levels of reflective activity (cf. Black and Plowright 2010). Not all reflection is critical reflection. Bolton (2010: 13) defined reflection (single loop activity) as 'an in-depth consideration of events or situations outside of oneself: solitary or with critical support', and reflexivity as a double loop process which includes reflection and reflexivity and is focused on 
'finding strategies to question our own attitudes, thought processes, values, assumptions, prejudices and habitual actions, to strive to understand our complex roles with others'. Wilson and Demetriou (2007) differentiate between three types of reflective practice: intensive action reflection which is seen as tacit, implicit and occurring on a daily basis in practice where individuals use intuitive tacit knowledge to inform practice (reflection-in-action); reactive or reflective learning (knowledge of action) involving immediate reactive reflection on events that have already taken place; and deliberative reflection (knowledge for action) involving the conscious management of thoughts and activity and the deliberate setting aside of time to ensure that judgements are based on a deep understanding of a particular issue.

Meta-cognitive learning refers to learners' awareness of their own knowledge and their ability to understand, control, and manipulate their own cognitive processes. Most meta-cognitive processes can be placed within three categories (cf. Harris and Graham 1999). The first is metamemorisation. This refers to the learners' awareness of their own memory systems and their ability to deploy strategies for using their memories effectively. The second is meta-comprehension. This refers to the learners' ability to monitor the degree to which they understand information being communicated to them, to recognize failures to comprehend, and to employ repair strategies. And the third is self-regulation. This term refers to the learner's ability to make adjustments in their own learning processes. The concept of self-regulation overlaps with meta-memorisation and meta-comprehension; its focus is on the capacity of the learners themselves to monitor their own learning (without external stimuli or persuasion) and to act independently. These regulatory processes may be highly automated, making articulation of them difficult for the learner.

A problem-solving approach is where the learner finds out for themselves rather than being given answers to problems. The learner is required to engage in a series of interrogative processes with regards to texts, people and objects in the environment, and come up with solutions to problems. The learner is also required to use the skills of information retrieval, information synthesis and analysis, and knowledge organization. The learner may come up with inadequate, incorrect and faulty syntheses and analyses. However, this is acceptable because the learning resides in the process 
rather than the end product. Problem-solving learning involves the learner in judging their own work against a curriculum standard and engaging in meta-processes of learning, that is, understandings about processes related to their own learning; the development of learning pathways; the utilisation of formative assessment processes; the development of personal learning strategies; and the internalisation of the curriculum.

Finally, there is practice. Practice is the act of rehearsing a behaviour over and over again, or engaging in an activity again and again. This reinforces, enhances and deepens the learning associated with the behaviour or activity. Choosing between these models depends on the nature and constitution of the learning object; in other words, the former is logically dependent on the latter. It also depends on the choice of learning theory that is made. Thus, the European cosmopolitan ideal, embraced by the European School System, has to be translated into a set of concrete pedagogic practices that do not in any way distort or neglect its underlying principles, and this involves making choices between the learning models discussed above: assessment for learning, observation, coaching, goalclarification, mentoring, peer learning, simulation, instruction, conceptformation, reflection, meta-cognitive learning, problem solving, and practice.

\section{Pedagogic Knowledge}

Knowledge is transformed at the pedagogic site, so it is possible to suggest that qualities such as: the simulation of the learning object, the representational mode of the object, its degree and type of amplification, control in the pedagogic relationship, progression or its relations with other learning objects (i.e. curriculum integration), the type of pedagogic text, relations with other people in the learning process, the organization of time (temporal relations) and types of feedback mechanism are fundamental components of this pedagogic transformation. What this means is that in the learning process, the learning object takes a new form as a result of changes to its properties: simulation, representation, amplification, control, integration, textual form, relations with other people, time and feedback. 
The first of these is the degree and type of simulation. In a simulation a new medium is chosen which gives the learning object a new form, these media being virtual, graphic, enumerative, enactive, symbolic or oral. Indeed, depending on the new form, there is a distance between the original object and the mediated object, and this can vary in strength. This doesn't mean that the object is better or less well represented in its new form, only that it takes on a new guise; it is pedagogically formed. And this means that its potential impact is likely to be different. A simulation might involve, for practical purposes, a computer representation of something in nature that cannot be experienced by the learner. Inevitably, the elements of the object and the relations between those elements are both reduced and changed in the simulation; and what this means is that any reaction or response to the object by a learner is influenced by its new media as well as the shape and form it now assumes. The response is always to the mediated object. And the implication of this is that the pedagogical relation between the learner and the world is never direct but is realised through the mediated object, with the process of knowing the unmediated object a retroductive one ('from a description and analysis of concrete phenomena to a reconstruction of the basic conditions for these phenomena to be as they are' - Bhaskar 2010: 34), although this may be understood in a different way by the learner.

A second property is the type of truth criterion that the knowledgeconstructor adopts. David Bridges (1999) itemised five conceptions of truth: truth as correspondence, truth as coherence, truth as what works, truth as consensus and truth as warranted belief. This property comprises a determination of the relationship between knowledge and the world, though it should never be assumed that this relationship is straightforward, linear or easily understood.

A third property, which is subject to transformation during the learning process, is amplification. Amplification is a central term in rhetoric, and stands for all the ways that an argument, explanation, or description can be expanded and enriched. In addition, amplification refers to the capacity of the pedagogic object to increase in size, in extent, or in effect, as by the addition of extra material. The use of a microscope in a science laboratory, or the use of the internet to extend the reach of the learning object, or the taking of a deliberate and alternative position from the accepted 
norm for the sake of debate or to further the argument, but always to deepen the learning process, are typical examples of amplification.

A fourth property is control in the pedagogic relationship. Framing refers to the message system of pedagogy (cf. Bernstein 2000). Do teachers and pupils control its content, its organisation, how it is sequenced, and so on? A syllabus with rigid topics, to be completed in a predetermined order, within a specified time, is strongly framed. Weak framing occurs when the teacher is able to select topics on the basis of some principle, and organise the sequence and pacing of material according to pupil readiness. Two control pathways can be identified. The first refers to the relationship between teacher and learner and the curriculum organisers of knowledge (these organising processes may be formal or informal), so a teacher or facilitator of the message system has either a restricted or extended control over the way it is received in the pedagogic setting. The second refers to the relationship between the teacher and learner and again this refers to the amount of control either one or the other has over the constitution of the message that is central to the pedagogic or learning process. Clearly, in this last case the one varies in relation to variation in the other.

A fifth property is curriculum integration or the types of relations between other learning objects. Progression is one manifestation of these relations. Curriculum standards, or learning objects, are written at different levels of difficulty. Most forms of progression between levels or grades in curricula round the world are based on a notion of extension, i.e. at level one a student should be able to do this or that, at level two the student is expected to be able to do more of this or that, and at level three the student is expected to be able to do even more of this or that. However, there are other forms of progression between designated knowledge sets, skills and dispositions besides extension. Indeed, some knowledge sets, skills and dispositions cannot be appropriately placed at some lower-level or even some higher-level grades. For example, many countries round the world have chosen not to start formal reading processes until at least seven years of age, and thus reading does not feature in the curriculum standards at pre-primary levels in these countries.

Fogarty (1991) has identified ten models of curriculum integration and these range from strongly classified and strongly framed curricula, as 
in the traditional or fragmented approach, to weakly classified and weakly framed networked approaches to curriculum planning (cf. Bernstein 1985). Between the two extremes: traditional or fragmented and networked approaches, she identifies eight other points on the continuum: connected, nested, sequenced, shared, webbed, threaded, integrated and immersed. Each of these forms of integration can only be understood in relation to their position on this continuum and in relation to how they approximate to one or the other of the end points of the continuum.

Finally, pace of learning is important, i.e. the pace at which a student works in completing a learning activity, or the pace at which they are expected to work against some norm, i.e. the average or mean of a population. Pace can be understood as a performative construct so that it is not meant to provide an empirical description of how a person has performed but is designed to act as a stimulus to increase the pace of learning for the general population; it thus has an explicit normative function.

A sixth property is the constitution of the task given to the learner in the pedagogic setting. As we suggested in Chap. 2, there is a range of learning tasks or activities that take place in classrooms, such as: working with other people, individual study, sharing, debating, playing games and so forth. Learning tasks have a number of constituent elements and how they differ in kind allows us to determine and identify these different elements: media of expression, the logic of this mediated expression, its fit with a learning model, its assessment mode, and its relation to real-life settings. Media of expression include: oral, graphic, pictorial and enumerative modes. Each of these media has an encompassing logic to them, so that a task which requires a written response to a request is of a different order as a learning experience to one which requires an oral response. A further component of a pedagogic task or activity is the mode of assessment that inheres in it, with these modes of assessment being understood broadly as formative or summative. Finally, there is the authenticity of the task and this refers to whether the task relates to real-life settings or not, or to the degree to which it does this.

The activity or learning task has a logical relationship with the learning model being employed. Frequently there is a mismatch between them so the task or activity (i.e. an oral response to a question, a written analysis of a text, a reading exercise, an argumentative response, a feed- 
back loop and so forth) and the type of learning model that is being adopted are incompatible. For example, a metacognitive exercise that is focused on propositional knowledge rather than process knowledge would be inappropriate. A dialogic peer-learning exercise that asked each participant to grade each other's work on a five-point scale again would be inconsonant. Feedback that failed to engage the learner in a conversation would not work.

Questioning, for example, sets up a choice situation between a finite range of possible answers. The type of answer that can be given legitimately has to be implicit in the grammar of the question, both in its form and content. For example, open-ended questions offer an infinite range of answers; that is, the restricting and enabling quality in the question is weakly formulated. What this means is that there is a greater range of possible answers to the problem. This has to be qualified in the sense that some questions by virtue of their propositional content have a greater facility for generating appropriate answers; whereas other questions have fewer possibilities for generating appropriate answers. However, this doesn't nullify the original proposition, which is that the form a question takes, placing this on an open-ended to closed-ended continuum, restricts or enables the types of correct answers that can be given to that question to different degrees. The reason for designating both an enabling and restricting function is to indicate that any action performed by an individual is located in discursive and material contexts and that these contexts exert an influence on the action itself.

A seventh property is the relationship between the learner and other people in the pedagogic setting. One way of characterising the relationship between the person, text, object in nature, particular array of resources, artefact, allocation of a role or function to a person, or sensory object and the learner is by determining its strength along a continuum ranging from a diffuse mode to a concentrated mode. What this means is that the message being conveyed is embedded in a relationship between the stimulus and recipient, which is either diffuse or concentrated, or could be placed on a continuum between them. An example of a diffuse strategy is an instructional mode of learning where the stimulus is being shared by a number of people. An example of a concentrated strategy is a one-to-one coaching relationship. What are the possible effects of these 
two types of learning? Since the relationship is both from the catalyst to the learner or learners and also from the learner or learners to the catalyst then this is going to influence the type of message received by the learner. We model the world as a sequence of messages passing from one to the other. The stimulus is clearly of a certain type. These are message conveyance systems or processes of semiotic transmission that operate with a particular stimulus denied to the learner if the stimulus for learning is different.

Learning is always embedded in temporal arrangements of one type or another. A curriculum is an arrangement of time given to different items of knowledge, so any learning episode is going to be embedded in these arrangements of time. These eight properties of the learning environment means that there is potentially a large range of possible environments since there is considerable variation within each dimension and in most cases variation in one dimension is independent of variation in the others. Finally, there are feedback mechanisms and again there is variation in this element.

Feedback is a systemic property (in the case we are considering here this is the learning process or system) and broadly consists of two types: feedback as it operates in closed systems and feedback as it operates in open systems. Hattie and Timperley (2007) use assessment feedback as a general concept to categorise definitions and types of feedback using the following dimensions: role, type, foci, meaning and function. Functionally, feedback has a scaffolding form and aims to bridge the gap between the level achieved by an individual learner and a normative level, which is subsequently used to amend that gap. Hannafin et al. (1993) distinguish between task, strategic and affective feedback. Task feedback is defined as providing activities that clarify or reinforce aspects of the learning task. Strategic feedback comprises diagnostic-prescriptive, performance, management, and process activities. Affective feedback is understood as a process of engaging learners through eliciting and sustaining their interest and engagement. Hattie and Timperley's (2007) four-fold model of levels of feedback (task, process, self-regulation and self) is an extension of this.

Black and Wiliam (1998) distinguish between directive (what needs to be changed) and facilitative (what processes can guide the learner to make those revisions to their work) types of feedback. Nelson and Schunn 
(2009), in developing this framework, identify three broad types: motivational, where the intention is to influence the beliefs of the learner and their willingness to participate in the learning activities; reinforcing, where the aim is to reward or to punish specific behaviours; and informational, where the purpose is to change the performance of the learner in a particular direction. They point to the importance of being able to develop knowledge through a transfer of learning so that it is applicable in new contexts. Thus feedback is understood as multi-functional in relation to different learning environments, the needs of the learner, the purpose of the task and the particular relation feedback has to the learning theory being employed. A directive approach to feedback fits better a cognitivist perspective where it is understood as corrective with the expert providing information to the passive recipient. Alternatively, facilitative feedback identifies more closely with a socio-constructivist view where feedback is seen as a process that takes place within a learning environment, without determining what those understandings will be. Significantly, these two perspectives should be seen as reinforcing rather than as opposite ends of a continuum. The socio-constructivist view is highlighted in the need to see feedback as an integral and iterative part of the learning context and within formative assessment frameworks that emphasise interactions between teachers, pupils and subjects within communities of practice. Furthermore, within a co-constructivist approach, it is also accepted that the teacher learns from the student through dialogue and participation in a range of shared experiences (cf. Lave and Wenger 1998). Within such environments, feedback is understood as iterative, adaptive and dynamic, with different learners receiving different types of feedback and this varies at different stages of the learning process, though this principle is sometimes neglected in classrooms in European system schools.

\section{Concluding Thoughts}

The European Schools Network has existed since the European Economic Community (EEC) was founded in 1953. The system has its own rules in terms of enrolment, funding and management, as well as its own 
curriculum. It was first created as an instrument to meet the educational needs of the children of the civil servants working in Luxembourg for the then newly formed European Union. The different stakeholders (i.e. parents, institution officials, civil servants and policy-makers) reached an agreement that these children should have the opportunity to be educated in their mother tongue, as well as having the same standard of education as their national classmates in their home countries.

It is important to remind ourselves that mother-tongue communication is more than a competence to be acquired but fulfills a cultural role at the very heart of the European Schools' project (from Jean Monnet's '...Without ceasing to look to their own lands with love and pride...' to being embodied in the First Objective and First Principle of the Schools.) The first principle of the European Schools System is to safeguard the 'primacy of the students' mother tongue' (L1), and the first objective of the European School System is to 'give students' confidence in their own cultural identity, the bedrock for their development as European citizens'.

The European schools' curriculum is generally of a fragmented or traditional type; and what we mean by this is that there are strong and clear boundaries between the different subjects. Our suggestion in this book is that in order to genuinely take into account the needs of students faced with the demands of the modern world; to conform to the accepted and logical principles of curriculum design; to be relevant, coherent, comprehensive, and allow breadth of study for all students in the system; to guarantee in the last two years, leading to the European Baccalaureate, a general education around the eight key competences for lifelong learning; and to impact favourably on specific groups, such as students without a language section, students with special educational needs, students with more than one national language and small language sections; then, existing subject boundaries need to be reduced and subject integration and networked approaches to curriculum need to be adopted.

If reform in the European Schools is to be truly valuable, it must go beyond arcane issues relating to institutions and structures, assessment processes, subject allocations and resourcing, and linguistic issues. It must take a braver moral position that has relevance for society as a whole, even setting the tone for wider debates where it can. The changes that have 
already been made, and those that are being considered, might seem as though they are a reaction to internal conditions, but they are actually rooted in a pressing need to consider issues relating to learners and their contemporary social identity. For this reason, it is important to ensure not only that the European Schools have an internal sense of common purpose, but also that this relates to changes in society going on outside their immediate learning environment. Only if this is achieved can a wide range of students receive a truly valuable education fit to meet individual, societal and global needs.

Open Access This chapter is licensed under the terms of the Creative Commons Attribution 4.0 International License (http://creativecommons.org/licenses/ by/4.0/), which permits use, sharing, adaptation, distribution and reproduction in any medium or format, as long as you give appropriate credit to the original author(s) and the source, provide a link to the Creative Commons license and indicate if changes were made.

The images or other third party material in this chapter are included in the chapter's Creative Commons license, unless indicated otherwise in a credit line to the material. If material is not included in the chapter's Creative Commons license and your intended use is not permitted by statutory regulation or exceeds the permitted use, you will need to obtain permission directly from the copyright holder.

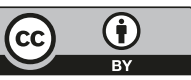

